\title{
From bench to bedside: use of human adipose-derived stem cells
}

This article was published in the following Dove Press journal:

Stem Cells and Cloning: Advances and Applications

2 November 2015

Number of times this article has been viewed

\author{
Vaughan Feisst ${ }^{1}$ \\ Sarah Meidinger' \\ Michelle B Locke ${ }^{2}$ \\ 'Dunbar Laboratory, School of \\ Biological Sciences, ${ }^{2}$ Department \\ of Surgery, Faculty of Medicine and \\ Health Sciences, The University of \\ Auckland, Auckland, New Zealand
}

Correspondence: Michelle B Locke Department of Surgery, Faculty of Medicine and Health Sciences, The University of Auckland, South Auckland Clinical Campus, 2nd Floor, Esme Green Building, c/- Middlemore Hospital, Private Bag 933II, Otahuhu, Auckland I640,

New Zealand

Tel +6421963533

Email michelle.locke@middlemore.co.nz

\begin{abstract}
Since the discovery of adipose-derived stem cells (ASC) in human adipose tissue nearly 15 years ago, significant advances have been made in progressing this promising cell therapy tool from the laboratory bench to bedside usage. Standardization of nomenclature around the different cell types used is finally being adopted, which facilitates comparison of results between research groups. In vitro studies have assessed the ability of ASC to undergo mesenchymal differentiation as well as differentiation along alternate lineages (transdifferentiation). Recently, focus has shifted to the immune modulatory and paracrine effects of transplanted ASC, with growing interest in the ASC secretome as a source of clinical effect. Bedside use of ASC is advancing alongside basic research. An increasing number of safety-focused Phase I and Phase IIb trials have been published without identifying any significant risks or adverse events in the short term. Phase III trials to assess efficacy are currently underway. In many countries, regulatory frameworks are being developed to monitor their use and assure their safety. As many trials rely on ASC injected at a distant site from the area of clinical need, strategies to improve the homing and efficacy of transplanted cells are also being explored. This review highlights each of these aspects of the bench-to-bedside use of ASC and summarizes their clinical utility across a variety of medical specialties.
\end{abstract}

Keywords: standardization, bystander effect, stromal cells, mesenchymal stem cells, stromal vascular fraction

\section{Introduction}

In 2001, Zuk et al demonstrated that multipotent mesenchymal stem cells (MSC), capable of differentiation into bone, fat, and cartilage, could be isolated from lipoaspirate. ${ }^{1}$ Since then, adipose-derived stem cells (ASC) have seen an exponential increase in their use in clinical trials across a wide range of diseases. ${ }^{2}$ ASC are very similar to bone marrow MSC (BMSC), which have been in clinical use for decades, but ASC have significant advantages, including greater potential cell yield from patients, a less invasive harvesting procedure, and therefore reduced morbidity. Initially, the focus of clinical translation for ASC was on their ability to differentiate into multiple lineages of interest to the field of regenerative medicine, particularly for regenerating cartilage and bone defects. Early clinical trial results showed some success, but investigations into the mechanisms of action revealed that it was not always the ability of ASC to differentiate into chondrocytes or osteoblasts that was producing clinical benefit, but often their ability to modulate the immune system which provided therapeutic effect. Since this realization, there has been a significant shift in focus for potential therapeutic use of ASC, toward treating inflammation-based diseases such as rheumatoid arthritis, Crohn's disease, and multiple sclerosis. The use of ASC to treat cartilage defects is 
still being investigated in clinical trials, but these are now running in parallel with investigations into the therapeutic benefit from ASC-induced reduction of inflammation, allowing natural regeneration processes to occur.

Although there has been some promising progress toward clinical use of ASC, there have also been a number of problems identified. Cell preparation, delivery methods, cell homing, engraftment, and ASC survival have all required investigation as researchers try to understand the mechanisms by which ASC can provide therapeutic benefits. We will discuss these issues in this review with respect to their importance in translating the use of ASC into therapeutic use.

\section{Definitions}

Stromal vascular fraction (SVF) is the pellet of cells produced when lipoaspirate is digested with collagenase (Figure 1). SVF contains immune cells, ASC, and endothelial progenitor cells, among others (Figure 2). ASC are commonly purified from SVF by adherent culture. SVF is plated in a cell culture dish, nonadherent cells are removed, and non-proliferative adherent cells are overgrown by ASC. Passaging removes nonadherent cells, hematopoietic cells, and endothelial cells, leaving behind a population of adherent, proliferative cells labeled ASC (Figure 2)..$^{2-4}$
Enzymatic digestion to isolate SVF, followed by adherent culture purification, was the original method published by Zuk et al to isolate cells and produce what they termed "PLA", now termed "ASC". ${ }^{1}$ Since this time, a number of alternative methods have been demonstrated for the isolation of ASC, including magnetic-activated cell sorting (MACS) and fluorescence-activated cell sorting, but to the best of the authors' knowledge, of the two, only MACS has been previously approved for use in a clinical setting. MACS isolation of ASC from SVF would be advantageous in a situation where cell number expansion was not required, and a defined cell population could be produced in a few hours for patient treatment, compared to adherent culture purification, which can take days to weeks. In a situation where cell expansion was required to obtain the required cell numbers for patient treatment, then there would be no need for MACS isolation when adherent culture of SVF would produce an ASC population with expanded cell number.

Both ASC and SVF have the potential to be used as therapeutics (Figure 1). SVF may have an advantage over ASC in the treatment of some diseases because of the presence of endothelial progenitor cells along with the ASC. The disadvantage to using SVF is that the number of cells that can be used for treatment is limited to what can be extracted from

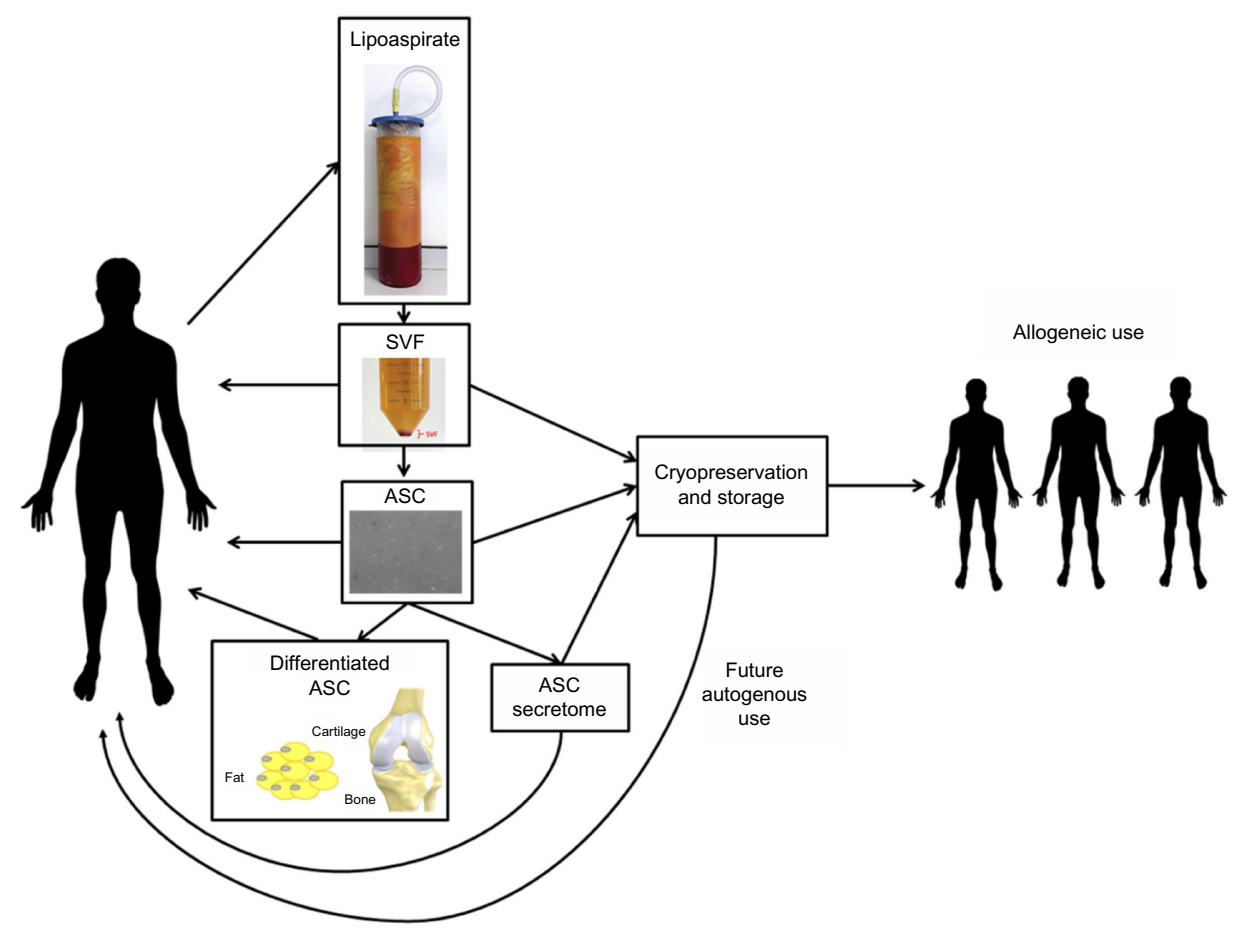

Figure I Isolation process and potential therapeutic products derived from lipoaspirate.

Notes: Lipoaspirate is harvested from a patient. Digestion with collagenase produces a stromal vascular fraction (SVF), a combination of immune cells, adipose-derived stem cells (ASC), endothelial progenitor cells, and others. ASC can be purified from SVF by culturing adherent proliferative cells and removing nonadherent cells. SVF and ASC are commonly used as autologous therapeutics and can be preserved for future use. Both SVF and ASC have the potential to be used as allogeneic therapeutics. Differentiated ASC and the factors secreted by ASC also have potential therapeutic use. 

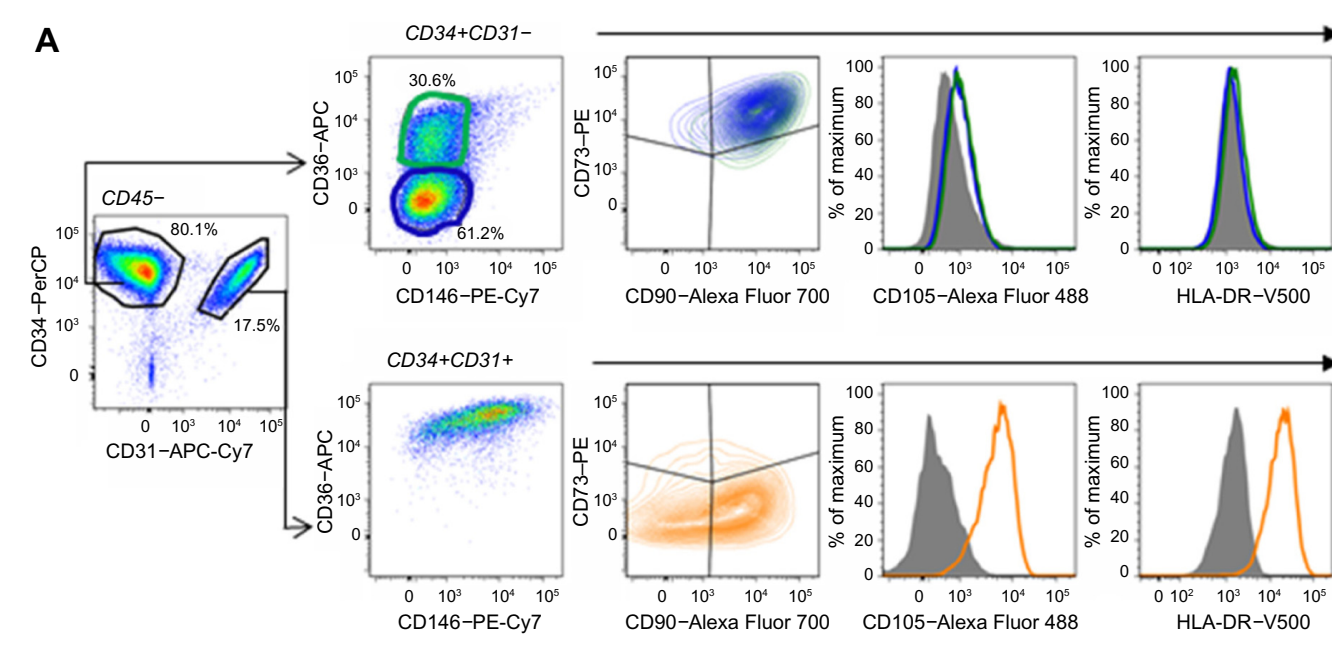

ASC
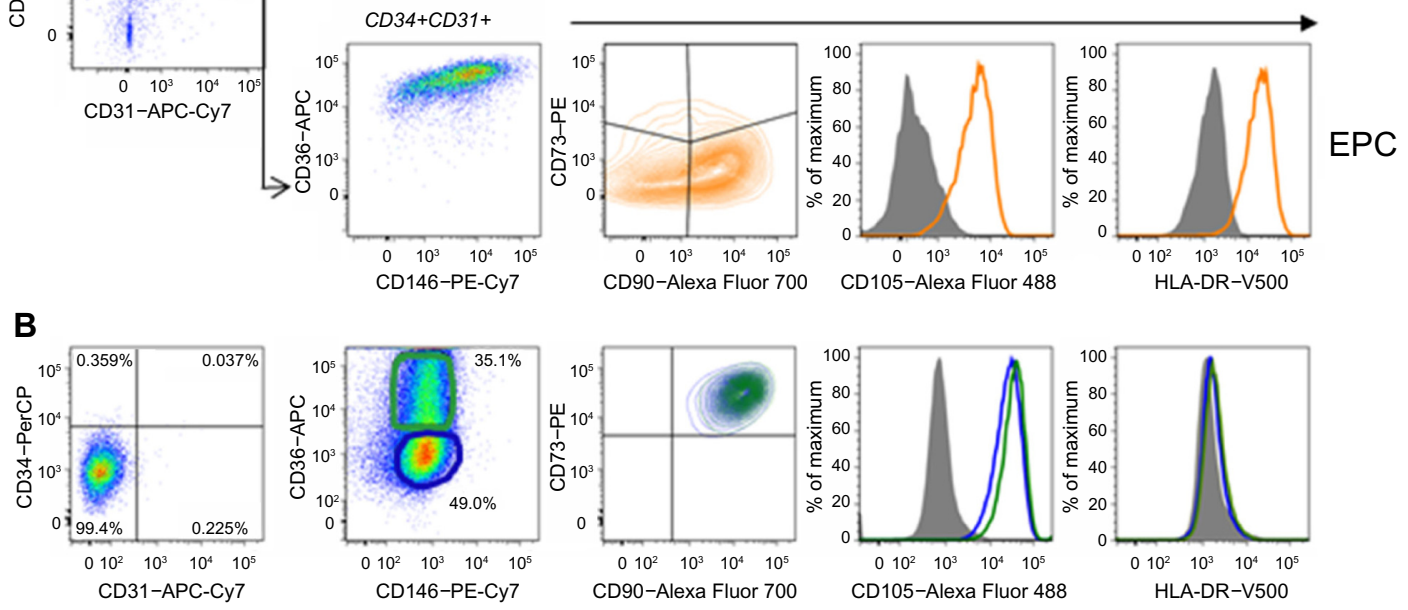

\begin{tabular}{|c|c|c|c|c|c|c|c|c|}
\hline & CD31 & CD34 & CD45 & CD73 & CD90 & CD105 & CD146 & HLA-DR \\
\hline SVF - EPC & + & + & - & - & $+/-$ & + & + +/low & + \\
\hline SVF - ASC & - & + & - & + & + & Low & - & - \\
\hline Adherent purified ASC & - & - & - & + & + & + & - & - \\
\hline
\end{tabular}

Figure 2 Fluorescence-activated cell sorting characterization of (A) nonhematopoietic (CD45-) cells of stromal vascular fraction (SVF) and (B) adherent purified adiposederived stem cells (ASC). (C) Summary of flow cytometry cell surface marker expression analysis for uncultured endothelial progenitor cells (EPC) in SVF, uncultured ASC in SVF, and adherent purified ASC.

Notes: SVF contains two main nonhematopoietic (CD45-) cell populations, ASC and EPC. When ASC are purified from SVF by adherent culture, CD34 expression is lost and CDI05 expression is increased. Adapted from Feisst V, Brooks AE, Chen CJ, Dunbar PR. Characterization of mesenchymal progenitor cell populations directly derived from human dermis. Stem Cells Dev. 2014;23(6):63I-642. ${ }^{3}$ Copyright $\odot 2014$.

the patient. Conversely, an advantage of using purified ASC over SVF is that an extended period of cell culture means that the cells can be expanded up to far greater numbers than initially isolated for greater therapeutic advantage. In this fashion, it is possible to produce very large numbers of cells for autogenous use or to establish a cell line for allogeneic use in a large number of patients.

\section{Standardization of SVF and ASC}

Clarification of the cell surface phenotype of ASC has been an important advance which has enabled the comparison of results of various clinical trials using ASC. It has been crucial to understand the dynamic expression of CD34 and CD105 on ASC because the International Society for Cellular Therapy (ISCT) defines an MSC as expressing cell surface phenotype CD34-, CD45-, CD73+, CD90+, CD105+, HLADR- ${ }^{5}$ ASC found in uncultured SVF do not fit this definition; they are CD34+ and CD105 ${ }^{\text {low }}$ (Figure 2). ${ }^{3,4}$ However, after adherent culture purification, ASC lose expression of CD34 and increase expression of CD105, consistent with the ISCT definition (Figure 2) ${ }^{3,4}$ To clear up any confusion, the ISCT and International Federation for Adipose Therapeutics and Science (IFATS) released a joint position statement clarifying these differences in the cell surface phenotype between ASC in SVF and ASC that had been adherent culture purified. ${ }^{2}$ Another issue that has affected the validity of previous outcome comparisons between clinical trials is the variation in therapeutic efficacy due to variability between donors (interpatient variability) and between the cell isolation and culture methods of different research groups. ${ }^{6-8}$ This variation of ASC efficacy between donors is potentially important within clinical trials using autologous cells because interpatient variability could be responsible for variation in the therapeutic efficacy demonstrated. Use of an allogeneic ASC line limits the donor variability, but variation between recipients as well as disease heterogeneity can still contribute 
differences in therapeutic efficacy of the product. Similarly, variable processing techniques between researchers can result in the clinical use of differing cell samples, with some groups utilizing fresh SVF while others may use purified, cultured ASC in their experiments, meaning that outcomes are hard to compare. For these reasons, some standardization of the nomenclature and potency of ASC is required in order to compare results across clinical trials.

The immunosuppressive abilities of ASC have been shown in vitro by assessing the ability of expanded ASC to suppress lymphocyte reactivity in mixed lymphocyte reaction assays ${ }^{9}$ and to inhibit the production of inflammatory cytokines. ${ }^{10}$ This and other evidence has enabled the use of allogeneic ASC as a therapeutic treatment for a number of diseases. The potency of their immunosuppressive ability is demonstrated by the fact that ASC have been trialed as a treatment for graft-versus-host disease and transplant rejection. ${ }^{11-13}$ The advantage of using allogeneic ASC is that cells from a single donor can potentially be used to treat all the patients in a trial, eliminating donor variance. In order to use ASC from a single donor in multiple patients, the cells must be expanded in culture to provide the numbers required for the clinical trial. However, this process can have a significant effect on ASC bioactivity. ${ }^{14}$ The US Food and Drug Administration (FDA) has suggested that standard assays are required in order to assess the bioactivity of the cells used in each clinical trial. In that way, therapeutic benefit can be linked to the potency of the cells used, and also allow for comparisons across clinical trials which have used cells from different donors at different stages of expansion.

Realizing that this variability has become a significant issue and that a large number of clinical trials have now been undertaken using ASC, the FDA (through its Center for Biologics Evaluation and Research [CBER]) have begun researching ways in which ASC bioactivity can be measured. The CBER is looking into the use of a standard assay to allow correlation of therapeutic effects with the bioactivity of the ASC in clinical trials. ${ }^{15,16}$ This will be a challenge because factors which are determined to be critical for the therapeutic use of ASC in one instance may not necessarily be similarly critical for the treatment of a different disease process.

Characterization of the cell surface phenotype by flow cytometry based on the definitions set out by the ISCT and IFATS will identify the cells. ${ }^{2}$ Simple functional assays will go some way to identifying the bioactivity of the cells used in the trial. Quantification of colony-forming units, adipogenic differentiation, and interleukin 10 secretion could be used to demonstrate the efficacy of each of the key activities of
ASC - namely, proliferation, differentiation, and immune modulation. In our experience, detection of fatty acid binding protein 4 expression - a marker of the adipogenic lineage - is an excellent method for quantifying adipogenic differentiation in an ASC culture. ${ }^{17}$ We await with interest the outcome of the CBER review on this issue.

\section{Administration of ASC for clinical use}

There are several different potential routes for delivery of ASC to diseased or injured tissues. ASC can be administered either by systemic, parenteral, or direct application or injection of ASC into the targeted tissue site for regeneration and repair.

The systemic delivery of ASC via intravenous, intraperitoneal, intra-arterial, or intracardial injection is dependent on the "native" homing of ASC to the site of disease or injury. ${ }^{18}$ Mesenchymal stem cells, including ASC, express cytokine and chemokine receptors on their cell surface, which is said to enable them to migrate to the site of the damaged tissue by chemotactic gradients secreted by the inflamed tissue. ${ }^{18}$ This "native" homing enables a targeted delivery of the stem cells to diseased sites. For instance, Cho et al showed that human ASC migrate into diseased tissue in an allergic rhinitis mouse model. ${ }^{19}$ The systemic administration of autologous ASC is a particularly promising option for treating patients with autoimmune disease such as autoimmune hearing loss, multiple sclerosis, polymyositis, atopic dermatitis, and rheumatoid arthritis. ${ }^{20}$ However, it remains uncertain how many ASC migrate to the targeted tissues following systemic administration. It has been shown that intravenous administration of ASC leads to accumulation mainly in the lungs but also in the liver, heart, and brain. ${ }^{18}$ Critics of systemic stem cell therapies point out that an increase in the number of injected ASC could lead to cell aggregates, which may produce pulmonary emboli or infarctions in the patient or disturb the blood flow. ${ }^{21}$

As an alternative to systemic delivery, local administration of ASC by in situ injections or topical application into the injured tissue can result in enhanced engraftment efficiency for the treatment of wounds. ${ }^{22}$ Local administration avoids the need of ASC to be homed by chemotactic gradients, as the ASC are directly applied into the targeted tissue. Direct application also avoids the potential risks of systemic administration discussed above. Tissue regeneration through direct application of ASC has been shown successfully in a number of tissues and disease conditions, including injection into the myocardium, local administration for bone regeneration, and topically for wound healing. ${ }^{18} \mathrm{Nie}$ et al demonstrated that the 
healing of wounds is accelerated through local administration of ASC in a rat model of excisional wound healing. ${ }^{23} \mathrm{How}-$ ever, despite high therapeutic efficiency in some cases, the practice of in situ administration carries with it a unique set of risks, as this procedure can be more invasive and cells are directly injected into a potentially incompatible microenvironment. ${ }^{24}$ Thus, administration routes for ASC therapy should be carefully considered before clinical application for optimal therapeutic efficiency.

\section{Clinical applications of ASC}

The ability of ASC to differentiate along mesenchymal lineages led to the original interest in their clinical use..$^{25}$ Initial research looked into the generation of adipose tissue, bone, and cartilage. Over the past decade, the scope of research into ASC has significantly expanded. Evidence of transdifferentiation (being the differentiation of mesenchymal lineage ASC into ectodermal or endodermal tissue types such as neurons ${ }^{26}$ or keratinocytes ${ }^{27}$ ) as well as evidence of their anti-inflammatory and immune-modulatory effects have broadened the field significantly (Figure 3 ). These latter roles have been termed "bystander effects", and may be the reason behind the wide scope of clinical applicability of ASC.

\section{Mesenchymal differentiation}

A considerable number of clinical trials utilizing the ability of ASC to differentiate along mesenchymal lineages have already been reported.

\section{Adipose tissue}

Not surprisingly, there is good evidence that ASC can differentiate into adipocytes to generate adipose tissue. ${ }^{25}$ Clinical trials in this field are therefore well progressed. In clinical practice, adipose tissue is used as a filler for contour deformities or volume enhancement. It has wide-ranging applicability in breast reconstruction or augmentation and facial rejuvenation, among other areas. Long-term survival of the transplanted fat depends on the ability of the adipocytes to generate a new blood supply. Under normal circumstances, a proportion of the transplanted tissue will undergo resorption over the subsequent postoperative months, presumably due to the lack of angiogenesis. This often results in the patient needing to undergo additional surgical procedures to obtain the desired long-term result. Current research is focused on methods to improve the survival of transplanted adipose tissue. ${ }^{28}$ Huss and Kratz recommend culturing and differentiation of ASC prior to reinjection, to ensure only viable preadipocytes are reinjected. ${ }^{29}$ This process relies on the patient undergoing the liposuction and reinjection as two separate procedures, increasing the time frame for treatment as well as the cost. An alternative strategy is cell-assisted lipotransfer. ${ }^{30}$ In this procedure, adipose tissue is harvested in a routine fashion and half of it is processed to extract the SVF. The extracted cells are then introduced into the non-processed portion of the lipoaspirate, resulting in ASC-rich fat which is reinjected. This enrichment is said to increase the long-term survival of the injected fat. ${ }^{31,32}$

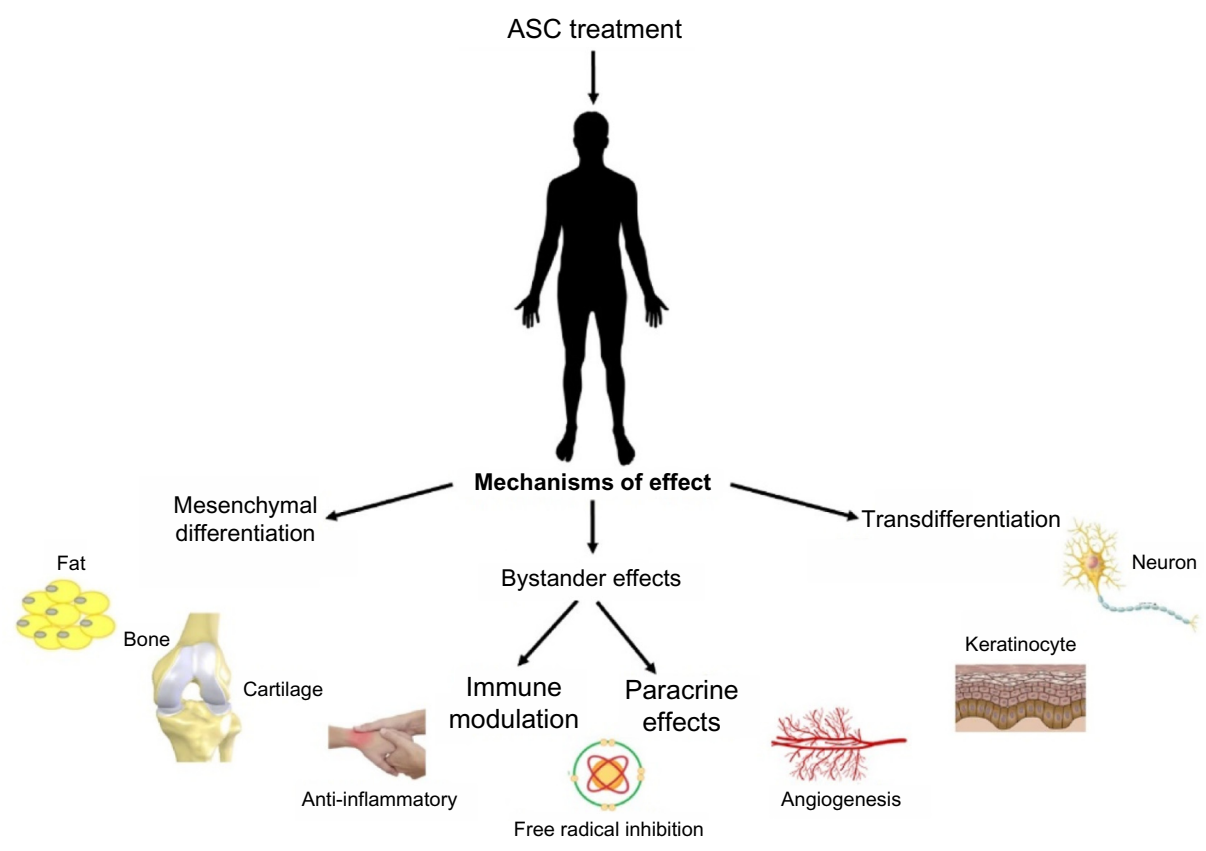

Figure 3 Potential mechanisms of effect of adipose-derived stem cells (ASC). 
It has the advantage of being able to be performed in a single surgical sitting, but does result in increased operative time and cost, with the cell processing taking approximately 90 minutes. ${ }^{32}$ There are also automated, closed-circuit processing systems which can perform this processing step, such as the Celution ${ }^{\circledR}$ System (Cytori Therapeutics, Inc., San Diego, CA, USA). ${ }^{33}$ An explosion of research in this field is on the horizon, as the Celution ${ }^{\circledR}$ System has been approved for use in Australia ${ }^{34}$ and the People's Republic of China in recent years, meaning there is likely to be a significant increase in its usage worldwide.

\section{Bone}

The human body has an innate ability to repair small bony defects and heal bone fractures. However, in clinical situations where bone healing is delayed or absent for reasons such as unfavorable biomechanics, presence of a large defect, or a poor wound-healing environment, there may be a role for ASC-assisted healing. The first report of the use of ASC in bony regeneration was a case of calvarial vault repair in a 7-year-old following head injury in $2004 .{ }^{35}$ While the treatment was effective clinically, SVF was used in this instance and combined with traditional bone graft and fibrin glue. Consequently, this demonstrates the previously highlighted lack of standardization in ASC research, as it becomes almost impossible to know how much the ASC contributed to the final clinical outcome. This is true for many examples of ASC osteogenesis in the literature. One key reason behind this fact is that, in contrast to some other modalities, clinically useful tissue-engineered bone is generally required to be a larger, three-dimensional (3D) construct. A small pellet of ASC alone would potentially not be considered sufficient treatment for a large bony defect, therefore either SVF or cultured ASC is combined with osteoconductive or osteoconducive substances such as calcium phosphate and bone morphogenetic proteins (BMP). In this fashion, clinical cases and small series have been reported utilizing ectopic bone constructs for craniofacial reconstructions of the maxilla ${ }^{36}$ and cranium ${ }^{37}$ and hyaluronic acid scaffolds for femoral head repair. ${ }^{38}$ Despite the promising initial studies, few clinical trials are currently registered looking at osteogenesis with ASC (Figure 4). This most likely reflects the challenges of large-scale, 3D bone generation in terms of time taken, manufacturing costs, and labor intensity. ${ }^{25}$

\section{Cartilage}

Osteoarthritis (also known as degenerative joint disease) is a common form of joint cartilage damage which results in pain, disability, and potential shortening of adult working life. ${ }^{39}$ Data from the UK suggests that the prevalence is as high as $25 \%$ of people over 50 years old and can result in joint replacement surgery due to the lack of effective treatments. ${ }^{39}$ Even limited areas of damaged cartilage do not heal well due to the poor vascularity of the intra-articular tissue. Therefore, regeneration of relatively small areas of diseased cartilage using ASC could have significant social and financial benefits. This is in contrast to bone regeneration, where larger areas of regeneration are generally required for clinical benefit. ${ }^{25}$

While numerous studies have shown the ability of ASC to differentiate into cartilage-producing cells as evidenced

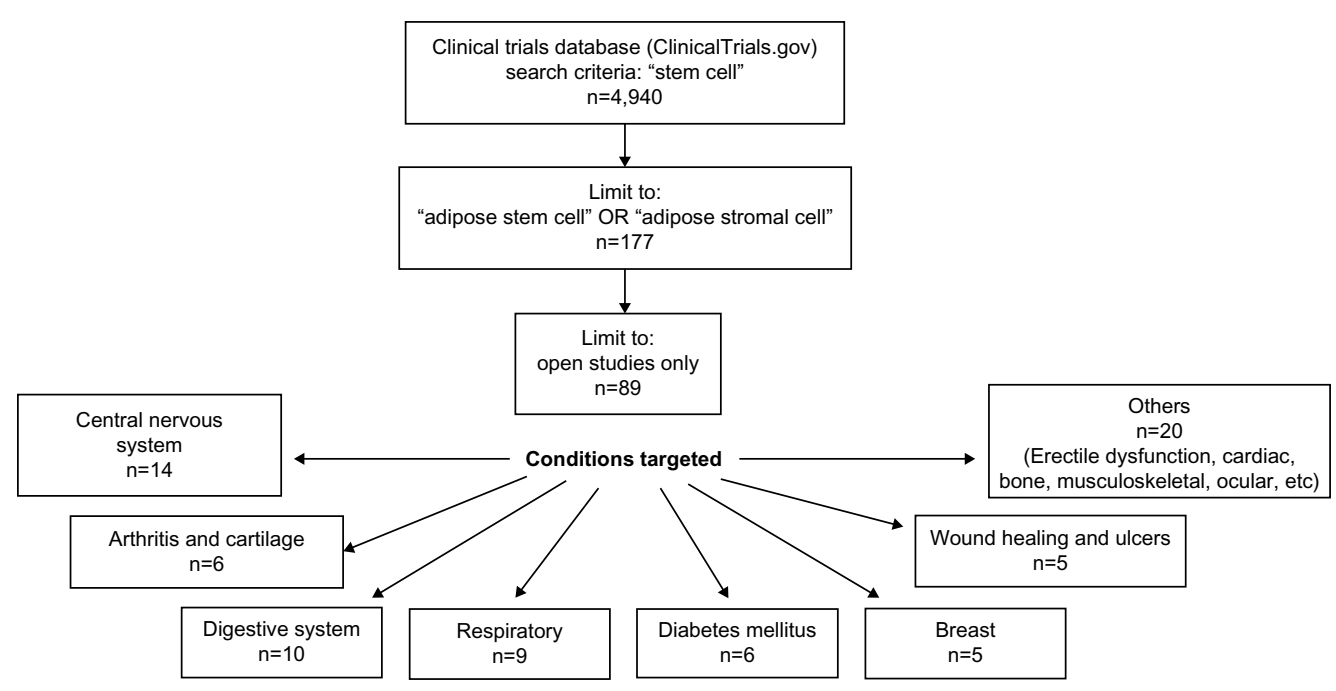

Figure 4 Clinical trials registered on http://www. ClinicalTrials.gov focused on adipose stem or stromal cells as at April 2015.

Notes: Only clinical trials which were currently open were included. Allocation to the single most appropriate "condition targeted" was made by the senior author from the clinical trial title and condition(s) listed. Each trial was therefore allocated to a single condition only. 
by positive Alcian blue or Safranin O staining, ${ }^{40-42}$ in vitro research looking at the growth of 3D cartilage blocks is still limited. Despite this, an early phase trial of intraarticular injection of ASC has already been performed in Seoul, South Korea by Jo and colleagues..$^{43}$ The primary outcomes of their trial were ASC safety and adverse events, but secondary outcomes of clinical and arthroscopic changes were also assessed. Early results with the small cohort of patients $(n=18)$ showed increased volume of hyaline-like cartilage on arthroscopy and self-reported decrease in symptoms of pain and functional limitations. ${ }^{43}$ However, some researchers suggest that BMSC show a greater ability to generate cartilage than ASC. ${ }^{44}$ This may be a contributing factor to the findings of a 2013 systematic review looking at the use of MSC in cartilage lesions. Filardo et al reviewed 90 papers on the topic, being 72 preclinical and 18 clinical trials, but only two of the clinical trials utilized ASC as the MSC of choice. ${ }^{45}$ Therefore, although regeneration of articular cartilage with ASC may be the holy grail of joint repair, clinical effects seen in previous trials may yet be shown to relate at least in part to anti-inflammatory or "bystander" properties of the cells rather than direct mesenchymal differentiation into cartilage.

\section{Bystander effect}

We understand the bystander effect to mean that transplanted stem cells are clinically effective due to their modulation of the host environment, rather than direct effects such as cell replacement or differentiation. ${ }^{46}$ The local tissue changes result from paracrine effects of the anti-inflammatory and cytoprotective molecules secreted by the transplanted cells. The bystander effect has been discussed in the setting of external beam radiotherapy since the early 1990s. ${ }^{47}$ Martino and Pluchino discussed the potential bystander effects of stem cell treatments in 2006 when discussing neural progenitor cells. ${ }^{48}$ They showed that BMSC induced recovery by elevating brain-derived neurotrophic factor (BDNF), neurotrophin-3 (NT-3), and vascular endothelial growth factor (VEGF) in rats with brain ischemia. That same year, other researchers showed that ASC have antioxidant effects, inhibiting $\mathrm{H}_{2} \mathrm{O}_{2}$-mediated apoptosis of cells in vitro. ${ }^{49} \mathrm{~A}$ metaanalysis of preclinical studies suggests that many MSC exert their effects through paracrine and immunomodulatory actions..$^{50}$ This has led to expansion of the field of ASC research to encompass many different clinical conditions. Much of the current research into ASC is now focused on immunomodulatory diseases and harnessing these bystander effects.

\section{Wound healing}

Perhaps surprisingly, the first published Phase I clinical trials utilizing ASC were in the treatment of recurrent or complex fistulae in patients with Crohn's disease in $2005 .{ }^{51}$ Eight patients were enrolled to test the safety of the treatment protocol, which involved direct injection of autologous ASC into the fistula sites. Despite the study not being designed to look at efficacy, six of the eight fistulae were considered healed at the end of the 8-week observation period. The authors then progressed to a Phase II clinical trial of 49 patients treated with either ASC and fibrin glue or fibrin glue alone, showing that a significantly higher proportion of patients treated with ASC healed in the follow-up period. ${ }^{52}$

Parallel with this work, preclinical studies have looked at the effect of ASC on wound healing. While delivery methods and outcome measures differ between studies, the published results seem to show that ASC promote wound healing through both differentiation and paracrine (trophic and anti-inflammatory) effects, ${ }^{53,54}$ even in patients with radiotherapy-damaged tissue. ${ }^{55}$ The wound-healing effects are mediated by secretory factors; hypoxia enhances these effects..$^{53}$ In one preclinical study, intradermal SVF injection has been shown to result in improved healing of a partial thickness scald burn in a rat, showing evidence of increased VEGF secretion and decreased inflammation in the treatment group. ${ }^{56}$ There is also evidence that ASC can transdifferentiate into keratinocytes and contribute to tissue-engineered skin, ${ }^{27}$ which may have a future role in the treatment of major burns. Clinical trials of ASC in cutaneous wound healing are largely limited to small case series. However, taken together, they seem to show utility in chronic and difficult wounds. Rigotti et al in Italy were the first to publish their experience in radiotherapy-damaged skin, detailing a series of 20 patients with chronic radiation-induced chest wall ulceration in 2007. Their patients were successfully treated over the previous 5 years with fat injections for their severe wounds. ${ }^{57}$ Their results have been replicated by other authors over the recent years, and ASC (or, more precisely, fat injections) are now being used for both treatment of late radiotherapy damage and as preconditioning treatment in an attempt to decrease surgical complication rates with elective surgery. ${ }^{58,59}$

\section{Treatment of cardiac disease}

According to the World Health Organization (WHO), cardiovascular disease has been the leading cause of death worldwide since $2008 .{ }^{60} \mathrm{MSC}$ research over the past 14 years has focused on restoring and regenerating cardiomyocyte 
function after myocardial infarction (MI) (heart attack) and heart failure. ${ }^{61,62}$ Studies with BMSC have shown improvements in ventricular function and myocardial regeneration within 72 hours of stem cell introduction, which is far earlier than would be expected with native repair mechanisms. ${ }^{63}$ While the exact stem cell biology underlying these changes are still poorly understood, these results have produced a prevailing theory of efficacy via bystander effects. ${ }^{61}$ To compare ASC and BMSC in the treatment of MI, one research group recently harvested both ASC and BMSC from an 84-year-old male patient undergoing coronary artery bypass surgery ${ }^{64}$ In a rat model with induced MI, the subjects were treated with intramyocardial injection of ASC, BMSC, or placebo (saline). The findings showed that both BMSC and ASC prevented left ventricle dilation but ASC alone improved left ventricle function at 4 weeks posttreatment. Interestingly, BMSC secreted significantly more VEGF than ASC, which is presumed to induce angiogenesis, but this did not result in a better angiogenic response, with neither the ASC nor BMSC group inducing significant myocardial angiogenesis. ${ }^{64}$ In progression toward Phase III clinical trials with ASC, the APOLLO study was published in $2012 .{ }^{65}$ The APOLLO study was a randomized, double-blind, placebo-controlled, Phase I/Ila study designed to assess the safety and feasibility of intracoronary infusion of ASC in the treatment of patients with acute MI. It enrolled 14 patients, of whom ten received ASC via the Celution ${ }^{\circledR}$ System and four received placebo injections. There were no serious adverse events recorded and the treatment group showed a trend toward improved cardiac function. This result is now being followed up in the ongoing ADVANCE Phase IIb/III clinical trial, which was initiated in May 2011 and hopes to enroll 375 patients with an ST-segment elevation MI. The results of this study may advance our bench-to-beside progression of ASC research significantly.

\section{Treatment of neural disorders}

ASC-based therapies have recently been investigated for the treatment of neural cell disorders. Early evidence suggests ASC have positive bystander effects and may also contribute through transdifferentiation. Schwann cells (SC), the primary neural cell in the peripheral nervous system, are required for nerve regeneration and repair after injury. ${ }^{66}$ To overcome clinical limitations from the slow growth rate of SC and harvesting challenges, ASC have recently been shown to transdifferentiate into SC in vivo. ${ }^{67,68} \mathrm{~A}$ small animal study that ASC could therefore be utilized to improve function recovery following nerve injury. ${ }^{69}$
Furthermore, investigation of ASC in the treatment of central nervous system disorders is also influenced by both transdifferentiation and bystander effects. There is evidence that ASC can differentiate into neuronal-like cell ${ }^{26}$ with a similar differentiation potential as BMSC but a higher proliferation capacity. ${ }^{70}$ To add to this, Carpentier and Palmer in 2009 established that immune signaling is influential on cell behavior, with proinflammatory cytokines having a negative effect on neurogenesis while anti-inflammatory cytokines have a positive neurotrophic effect. ${ }^{71}$ Therefore, ASC have recently been investigated for use in Parkinson's disease, which results from death of the dopamine-producing cells in the substantia nigra. A mouse model was used to assess the ability of ASC to aid neuroregeneration, with results showing that both intravenous and transcerebral injection of ASC greatly improved memory impairment. ${ }^{72}$ The exact mechanisms of the therapeutic effects were unable to be completely elucidated but were considered to potentially be threefold: migration and differentiation into neurons; bystander effects of cytokine secretion; and promoting activation of native microglia which secrete neurotrophin.

Another aspect of the central nervous system which is the subject of MSC research is spinal cord injury (SCI). According to the WHO, every year, between 250,000 and 500,000 people around the world sustain an SCI, which is associated with significant health, economic, and social consequences. ${ }^{73}$ Steroids are commonly used to treat acute SCI, but due to doubt regarding their clinical benefit, MSC have recently been investigated. ${ }^{74}$ One research group working with a rat model has shown that intravenous infusions of oligodendrocyte precursor cells derived from rat ASC result in significant improvements in motor function. ${ }^{49}$ However, another rat model of SCI suggested that, regardless of origin (rat ASC, BMSC, or subventricular zone), less than $1 \%$ of the cultured neurospheres injected actually survived and differentiated into oligodendrocytes. ${ }^{75}$ This suggests that bystander effects rather than transdifferentiation may be the primary mechanism of effect of ASC in the treatment of SCI.

\section{Other clinical uses of ASC}

In addition to the above, ASC are being investigated for a myriad of different conditions, with variable results. A Phase Ib clinical trial of endobronchial infusions of SVF for the treatment of pulmonary fibrosis showed no adverse events, but no functional improvements in the 14 patients either. ${ }^{76}$ With regard to potential diabetes mellitus treatments, ASC and BMSC have been investigated in vitro and in vivo in a rat model for the ability to support regeneration and differentiate 
of pancreatic islet cells by co-culture experiments. The rats treated with MSC showed improved weights and insulin tolerance, with ASC showing the best results. ${ }^{77}$ Patients with type 1 diabetes have also been co-infused with insulin-secreting cells derived from ASC, with improvements in insulin sensitivity. ${ }^{78}$ The immunomodulatory effects of ASC have been harnessed with investigations into the treatment of graft-versus-host disease and transplant rejection. ${ }^{12,79}$ Evidence that implanted ASC can restore dystrophin expression in a mouse model of Duchenne muscular dystrophy suggests that ASC may have potential uses in skeletal muscle disorders as well as genetic degenerative disorders. ${ }^{80-82}$

\section{Current ASC clinical trials}

As evidenced above, there is already a large body of published research into the many potential uses of ASC. Looking ahead to assess the future of this field, we have analyzed the US National Institutes of Health (NIH) website http://www. ClinicalTrials.gov, to review the focus of current clinical trials involving ASC. According to the website information the site was created by the NIH and the FDA and made available to the public in 2008 to fulfill the FDA's legal requirements that certain types of trials be registered. It provides access to information on publicly and privately funded clinical studies on a wide range of diseases and conditions.

An advanced search was performed to identify all current trials involving the use of ASC. Initial screening for stem cell research revealed 4,940 trials, of which only 177 (3.6\%) involved the use of ASC. To ensure all ASC trials were included, the search terms included both "adipose stem cell" and "adipose stromal cell". This was further limited to open studies only, to exclude those which had already been completed and reported on since the website began in 2008 . This left 89 trials which were individually analyzed by the senior author (MBL) (Figure 4).

When analyzed by condition targeted, the largest number of studies were investigating the use of ASC in neurological disorders $(n=14)$. This was a heterogeneous group, including cerebral vascular accident (stroke) treatment as well as use of ASC in SCI and degenerative neurological disorders such as multiple sclerosis and Parkinson's disease. The second most common use was in the digestive system, largely for the treatment of fistulae resulting from inflammatory bowel disease. However, the most interesting finding was the large number of different systems investigated. Many had five or fewer trials, but the range of sites and conditions was broad, encompassing everything from ocular anomalies to erectile dysfunction; from the respiratory system to musculoskeletal issues. This suggests that, in the near future, ASC may be shown to have widespread use across a broad range of conditions and diseases.

\section{Strategies to improve the efficacy of ASC therapies}

When designing cell-based regenerative strategies, several aspects have to be optimized to achieve the best possible results. The most appropriate site, timing, and mode of cell transplantation is important for clinical efficacy, while the ability to track the implanted cells is vital to ensure appropriate migration, survival, and differentiation following injection. ${ }^{83}$ To increase the efficiency of stem cell therapy, current research is focused mainly on strategies to improve the appropriate trafficking of stem cells after systemic or local application.

\section{Homing}

There are different strategies to improve the homing of systemically delivered ASC. Firstly, it has been shown that freshly isolated MSC compared to cultured MSC show enhanced homing. ${ }^{84}$ This is due to the fact that culturing MSC results in alterations to the expression of their cell surface receptors such as the $\mathrm{C}-\mathrm{X}-\mathrm{C}$ chemokine receptor type 4 (CXCR4), which are necessary for homing. ${ }^{84}$ To counteract this loss, expression of CXCR4 can be induced in culture using a cytokine cocktail, which has been shown to promote the migratory potential of MSC. ${ }^{85}$ Furthermore, culturing under hypoxic conditions can increase CXCR4 expression and thereby enhance the stem cell migration in response to SDF- $1 \alpha$ of ASC in vitro. ${ }^{86}$ Another strategy to influence the response of ASC to migratory stimuli is the modification of the gene expression of surface markers. An example of this would be inducing overexpression of CXCR4 via viral transduction to increase the homing ability of ASC for tissue regeneration. ${ }^{87,88}$

\section{Preconditioning}

Stem cells can not only be preconditioned in order to enhance their homing abilities, but also to "prime" the cells. This can lead to improved survival, increased paracrine effects, and enhanced differentiation potential. ASC can be preconditioned or manipulated before administration by chemical, physical, genetic, or molecular stimulation, thereby increasing the therapeutic effect of cell-based therapies. On a molecular level, the combination of gene therapy and stem cell therapy has recently been shown to increase the therapeutic efficiency of cell-based therapies. Transduction with viral vectors can 
genetically modify ASC to enable their use as a vehicle for gene delivery, to overexpress growth factors or cytokines, for instance into wounds. ${ }^{89,90}$ Furthermore, the addition of the pancreatic duodenal homeobox $1(\mathrm{Pdx} 1)$ gene to ASC via lentiviral transduction has been shown to promote insulin expression and potentially treat diabetes in mice. ${ }^{91}$ However, genetic modification using lentiviruses or retroviruses raises similar safety concerns as previously associated with gene therapy, and thus raises caution for translation into clinical application. Viral transduction introduces the potential risk of tumor formation, as there is a significant risk of integration into the host genome. This may lead to insertional mutagenesis, activation of oncogenes, transgene reactivation, and potentially epigenetic changes. ${ }^{92}$ In this regard, adenoviral vectors are a safer alternative, as they cannot integrate into the host genome. ASC transduced with adenoviral vectors expressing BMP2 improved bone formation in immunodeficient mice by implanting scaffolds loaded with the transfected ASC into the hind limbs. ${ }^{93}$ Moreover, preconditioning of ASC without the use of viral vectors has been explored in order to increase the therapeutic efficacy of ASC application. Inhibition of phosphodiesterase-5 in ASC by either sildenafil or genetic knockdown using short hairpin RNA improved the efficiency of the stem cell therapy in mice following MI after intramyocardial injection. ${ }^{94}$ Also hypoxic or anoxic culturing conditions to precondition MSC have been shown to enhance the survival of stem cells. ${ }^{95}$

\section{Coadministration}

Coadministration of ASC and drugs or biomolecules can be a powerful approach for therapy. The advantage of coadministration can be the usage of lower doses of drugs, potentially avoiding systemic toxicity. ${ }^{96}$ It has been shown that tumors release a number of cytokines, which recruits ASC into tumors, enabling ASC to be used as vehicles for cancer drugs, despite the fact that ASC may have some cancer-promoting potential by promoting angiogenesis and influencing the tumor environment. ${ }^{97,98}$ Grisendi et al transduced human ASC with a retroviral vector expressing tumor necrosis factor-related apoptosis inducing ligand (TRAIL). These transduced ASC reduced the size of cervical carcinoma tumors in xenotransplant mouse models in vivo and exerted cytotoxic effects in vitro on tumor cell lines such as breast cancer, cervical carcinoma, colon cancer, and pancreatic cancer cells. ${ }^{99}$ Coadministration of prodrugs to cancer sites is a particular focus of research. This approach, also called stem cell-mediated suicide gene therapy, is based on genetically modified stem cells that express an enzyme which converts a coadministered, nontoxic prodrug into a cytotoxic drug, killing neighboring cells via the bystander effect. ${ }^{100}$ Choi et al in 2012 showed that genetically modified ASC used as a vehicle for prodrug gene therapy are therapeutically beneficial in treating brainstem glioma in a rat model. ${ }^{101}$ Furthermore, investigators revealed recently that ASC expressing yeast cytosine deaminase::uracil phosphoribosyltransferase (CDy::UPRT) in combination with 5-fluorocytosine as prodrug are capable of successfully treating intracerebral rat glioblastoma. ${ }^{102}$ Due to the concerns around the uncertainty of whether ASC may promote tumor growth or even form tumors themselves, rigorous testing of genetically modified ASC is required before clinical application. However, in the case of stem cell-mediated suicide therapy, this concern is alleviated, as the stem cells are eliminated following their therapeutic effect. ${ }^{100}$ Thus, ASC may be an attractive pharmaceutical delivery tool in oncology, or genetically modified ASC can be used as a delivery vehicle for cytokines and signaling molecules.

\section{ASC as an "off-the-shelf" product}

The use of ASC as an allogeneic "off-the-shelf" product has advantageous aspects, due to the potential ease and speed of availability. Therefore, this aspect of their use is being investigated by several companies and researchers at present.

\section{Allogeneic transplantation of ASC}

As stated earlier, MSC including ASC have immunomodulatory properties. ASC have been shown to control graft-versushost-disease in preclinical and clinical studies. ${ }^{11,12,103,104}$ Furthermore, ASC are able to exert immunosuppressive effects on a host through prostaglandin E2 expression as well as a lack of expression of major histocompatibility complex II (MHCII). ${ }^{105}$ Thus, the immunomodulatory properties of ASC enable their allogeneic transplantation. Common concerns of stem cell therapy can include development of unwanted cell types, malignant transformation, and loss of function. Furthermore, the potency of autologous stem cell transplantation may vary between donors due to their age and disease state. Allogeneic ASC transplantation for therapeutic purposes may alleviate those issues. The possibility of an allotransplant combines the benefits of easier handling as well as simpler standardization of the therapeutic product. Allogeneic cells would not only be immediately available for the treatment of the patient, eliminating the need for a liposuction and processing step, but also could be isolated from healthy 
donors, potentially preselected based on their cytokine and cell marker expression profile to improve the therapeutic potential of the cells. A number of companies are currently producing allogeneic "off-the-shelf" ASC therapy products for the treatment of osteoarthritis, perianal fistula, and MI. Several of these products are currently in late-stage clinical trials. One example is produced by TiGenix N.V. (Leuven, Belgium). Their Cx601 product is an allogeneic, expanded ASC suspension which is currently in Phase III of clinical development for the treatment of complex perianal fistula in Crohn's disease by intralesional injection.

\section{Cell-free approaches for therapy}

Paracrine actions of ASC are likely to be one of the primary mechanisms of the therapeutic effect of ASC, as it has been shown that the use of a conditioned medium without cells can reproduce the same effect as ASC transplantation. ${ }^{106}$ Thus, the cell itself may not be required for clinical efficacy, which would potentially lessen the regulatory burden of the treatment. In particular, extracellular vesicles released from the endosomal compartment have great potential as a cellfree therapy for a variety of inflammatory diseases. These vesicles can contain biomolecules from the original stem cell such as proteins and genetic material including mRNA and miRNA. ${ }^{107}$ Numerous animal studies proved that MSCderived extracellular vesicles possess therapeutic potential for a range of disorders such as cardiovascular disease, acute kidney injury, liver injury, lung injury, and wound healing. ${ }^{107}$ For example, Arslan et al showed that intravenous injection of MSC-derived extracellular vesicles reduced the MI size in mice by $45 \%$ and improved cardiac performance, as well as reducing inflammation. ${ }^{108}$ In addition, the potential of long-term storage of the vesicles without a loss of function establishes a real potential for an "off-the-shelf" product. ${ }^{107}$ The use of ASC extracellular vesicles may be safer for clinical application when compared with whole-stem-cell therapy due to a lower risk of triggering an immune response in the patient and lack of tumorigenicity of the vesicles themselves. However, as concerns around the use of MSC in general relate to their potential ability to promote tumor growth, the secretome of ASC may also exert similar effects. Consequently, the safety of extracellular vesicles has to be sufficiently investigated before the translation into clinical usage.

\section{Barriers to clinical use}

Currently, the therapeutic use of ASC, and indeed all MSC, is hampered by a lack of understanding of the behavior and mechanisms of action of transplanted cells. ${ }^{109}$ There are also inherent differences between many clinical trials due to the differing methods of cell isolation and preparation which are employed, leading to transplantation of subtly different cell populations. Human clinical trials are often challenging to adequately compare, due to the heterogeneity of the patients and diseases being investigated.

In vivo, ASC reside in complex microenvironments. Variations in cell signals or responses can alter the functional pathway of the cells. ${ }^{110}$ In vitro research investigates cell functioning in isolation, and hence the clinical implications can be difficult to interpret. Clinical trials involve the delivery of ASC or its derivative cells into patients with a broad spectrum of disease signs and symptomatology. The ideal use of stem cell therapy would offer individualized treatment to each patient. However, taking into account the heterogeneity and complexity of diseases treated, such attempts could be limited to trial and error at the beginning of treatment use. ${ }^{109}$

\section{Conclusion}

The use of ASC as a clinical tool has progressed significantly over the past decade. While many clinical applications of ASC still make use of the traditional mesenchymal differentiation and proliferation principles, the concept of ASC affecting neighboring cells via cytokine release or other paracrine mechanisms (the "bystander effect") is rapidly broadening the therapeutic potential of ASC as a cell therapy. As a consequence, current ASC research spans the bench-to-bedside journey.

Preclinical research investigating the basic science of ASC-to-local-cell interactions and the complexity of the microenvironment are vital to understand and harness bystander effects. Ongoing investigations into effective preconditioning of cells prior to transplantation and strategies to improve their homing are the scientific foundations upon which the utility of ASC as a systemic treatment will rely. Meanwhile, further safety and efficacy clinical trials are underway to delineate the most clinically effective usage of ASC. These will need to be combined with long-term follow-up to obviate concern around the potential for transplanted ASC to contribute to carcinogenesis.

The medical need for efficient cell therapy is unwavering. ASC are one promising tool in this arena. We expect that the combination of current preclinical research and clinical trials will stimulate rapid progression to beneficial clinical usage of these cells over the coming years. 


\section{Disclosure}

The authors report no conflicts of interest in this work.

\section{References}

1. Zuk PA, Zhu M, Mizuno H, et al. Multilineage cells from human adipose tissue: implications for cell-based therapies. Tissue Eng. 2001;7(2): 211-228.

2. Bourin P, Bunnell BA, Casteilla L, et al. Stromal cells from the adipose tissue-derived stromal vascular fraction and culture expanded adipose tissue-derived stromal/stem cells: a joint statement of the International Federation for Adipose Therapeutics and Science (IFATS) and the International Society for Cellular Therapy (ISCT). Cytotherapy. 2013; 15(6):641-648.

3. Feisst V, Brooks AE, Chen CJ, Dunbar PR. Characterization of mesenchymal progenitor cell populations directly derived from human dermis. Stem Cells Dev. 2014;23(6):631-642.

4. Braun J, Kurtz A, Barutcu N, Bodo J, Thiel A, Dong J. Concerted regulation of CD34 and CD105 accompanies mesenchymal stromal cell derivation from human adventitial stromal cell. Stem Cells Dev. 2013;22(5):815-827.

5. Dominici M, Le Blanc K, Mueller I, et al. Minimal criteria for defining multipotent mesenchymal stromal cells. The International Society for Cellular Therapy position statement. Cytotherapy. 2006;8(4):315-317.

6. Mendicino M, Bailey AM, Wonnacott K, Puri RK, Bauer SR. MSCbased product characterization for clinical trials: an FDA perspective. Cell Stem Cell. 2014;14(2):141-145.

7. Koellensperger E, Bollinger N, Dexheimer V, Gramley F, Germann G, Leimer U. Choosing the right type of serum for different applications of human adipose tissue-derived stem cells: influence on proliferation and differentiation abilities. Cytotherapy. 2014;16(6):789-799.

8. Roldan M, Macias-Gonzalez M, Garcia R, Tinahones FJ, Martin M. Obesity short-circuits stemness gene network in human adipose multipotent stem cells. FASEB J. 2011;25(12):4111-4126.

9. Cui L, Yin S, Liu W, Li N, Zhang W, Cao Y. Expanded adiposederived stem cells suppress mixed lymphocyte reaction by secretion of prostaglandin E2. Tissue Eng. 2007;13(6):1185-1195.

10. Gonzalez-Rey E, Gonzalez MA, Varela N, et al. Human adipose-derived mesenchymal stem cells reduce inflammatory and $\mathrm{T}$ cell responses and induce regulatory T cells in vitro in rheumatoid arthritis. Ann Rheum Dis. 2010;69(1):241-248.

11. Fang B, Song Y, Liao L, Zhang Y, Zhao RC. Favorable response to human adipose tissue-derived mesenchymal stem cells in steroid-refractory acute graft-versus-host disease. Transplant Proc. 2007;39(10):3358-3362.

12. Fang B, Song Y, Lin Q, et al. Human adipose tissue-derived mesenchymal stromal cells as salvage therapy for treatment of severe refractory acute graft-vs-host disease in two children. Pediatr Transplant. 2007;11(7): 814-817.

13. Fang B, Song Y, Zhao RC, Han Q, Lin Q. Using human adipose tissue-derived mesenchymal stem cells as salvage therapy for hepatic graft-versus-host disease resembling acute hepatitis. Transplant Proc. 2007;39(5):1710-1713.

14. Park H, Cho JA, Lim EH, et al. Cell cycle regulators are critical for maintaining the differentiation potential and immaturity in adipogenesis of adipose-derived stem cells. Differentiation. 2011;82(3):136-143.

15. Lo Surdo J, Bauer SR. Quantitative approaches to detect donor and passage differences in adipogenic potential and clonogenicity in human bone marrow-derived mesenchymal stem cells. Tissue Eng Part C Methods. 2012;18(11):877-889.

16. Lo Surdo JL, Millis BA, Bauer SR. Automated microscopy as a quantitative method to measure differences in adipogenic differentiation in preparations of human mesenchymal stromal cells. Cytotherapy. 2013;15(12):1527-1540.

17. Aldridge A, Kouroupis D, Churchman S, English A, Ingham E, Jones E. Assay validation for the assessment of adipogenesis of multipotential stromal cells-a direct comparison of four different methods. Cytotherapy. 2013;15(1):89-101.
18. Katz AJ, Mericli AF. Stem cells derived from fat. In: Atala A, Lanza R, Thomson JA, Nerem R, editors. Principles of Regenerative Medicine. 2nd ed. San Diego: Academic Press; 2011:365-381.

19. Cho KS, Park HK, Park HY, et al. IFATS collection: immunomodulatory effects of adipose tissue-derived stem cells in an allergic rhinitis mouse model. Stem Cells. 2009;27(1):259-265.

20. Ra JC, Shin IS, Kim SH, et al. Safety of intravenous infusion of human adipose tissue-derived mesenchymal stem cells in animals and humans. Stem Cells Dev. 2011;20(8):1297-1308.

21. Prockop DJ, Olson SD. Clinical trials with adult stem/progenitor cells for tissue repair: let's not overlook some essential precautions. Blood. 2007;109(8):3147-3151.

22. Rigol M, Solanes N, Farré J, et al. Effects of adipose tissue-derived stem cell therapy after myocardial infarction: impact of the route of administration. J Card Fail. 2010;16(4):357-366.

23. Nie C, Yang D, Xu J, Si Z, Jin X, Zhang J. Locally administered adiposederived stem cells accelerate wound healing through differentiation and vasculogenesis. Cell Transplant. 2011;20(2):205-216.

24. Muschler GF, Nakamoto C, Griffith LG. Engineering principles of clinical cell-based tissue engineering. J Bone Joint Surg Am. 2004; 86-A(7):1541-1558.

25. Locke M, Feisst V, Dunbar PR. Concise review: human adipose-derived stem cells: separating promise from clinical need. Stem Cells. 2011; 29(3):404-411.

26. Ning H, Lin G, Lue TF, Lin CS. Neuron-like differentiation of adipose tissue-derived stromal cells and vascular smooth muscle cells. Differentiation. 2006;74(9-10):510-518.

27. Chavez-Munoz C, Nguyen KT, Xu W, Hong SJ, Mustoe TA, Galiano RD. Transdifferentiation of adipose-derived stem cells into keratinocyte-like cells: engineering a stratified epidermis. PLoS One. 2013;8(12):e80587.

28. Sajjadian A, Tandav Magge K. Treating facial soft tissue deficiency: fat grafting and adipose-derived stem cell tissue engineering. Aesthet Surg J. 2007;27(1):100-104.

29. Huss FR, Kratz G. Adipose tissue processed for lipoinjection shows increased cellular survival in vitro when tissue engineering principles are applied. Scand J Plast Reconstr Surg Hand Surg. 2002;36(3): 166-171.

30. Matsumoto D, Sato K, Gonda K, et al. Cell-assisted lipotransfer: supportive use of human adipose-derived cells for soft tissue augmentation with lipoinjection. Tissue Eng. 2006;12(12):3375-3382.

31. Yoshimura K, Sato K, Aoi N, Kurita M, Hirohi T, Harii K. Cell-assisted lipotransfer for cosmetic breast augmentation: supportive use of adiposederived stem/stromal cells. Aesthetic Plast Surg. 2008;32(1):48-55; discussion 56-57.

32. Yoshimura K, Sato K, Aoi N, et al. Cell-assisted lipotransfer for facial lipoatrophy: efficacy of clinical use of adipose-derived stem cells. Dermatol Surg. 2008;34(9):1178-1185.

33. Fraser JK, Hicok KC, Shanahan R, Zhu M, Miller S, Arm DM. The Celution ${ }^{\circledR}$ System: automated processing of adipose-derived regenerative cells in a functionally closed system. Adv Wound Care (New Rochelle). 2014;3(1):38-45.

34. Cytori Therapeutics. Cytori’s Celution ${ }^{\circledR}$ System approved in Australia for processing and delivering adipose-derived regenerative cells [press release]. San Diego: Business Wire; 2013 [August 7]. Available from: http://ir.cytori.com/investor-relations/News/news-details/2013/ Cytoris-Celution-System-Approved-in-Australia-for-Processingand-Delivering-Adipose-Derived-Regenerative-Cells/default.aspx. Accessed April 24, 2015.

35. Lendeckel S, Jödicke A, Christophis P, et al. Autologous stem cells (adipose) and fibrin glue used to treat widespread traumatic calvarial defects: case report. J Craniomaxillofac Surg. 2004;32(6):370-373.

36. Mesimäki K, Lindroos B, Törnwall J, et al. Novel maxillary reconstruction with ectopic bone formation by GMP adipose stem cells. Int J Oral Maxillofac Surg. 2009;38(3):201-209.

37. Thesleff T, Lehtimäki K, Niskakangas T, et al. Cranioplasty with adipose-derived stem cells and biomaterial: a novel method for cranial reconstruction. Neurosurgery. 2011;68(6):1535-1540. 
38. Pak J. Autologous adipose tissue-derived stem cells induce persistent bone-like tissue in osteonecrotic femoral heads. Pain Physician. 2012;15(1):75-85.

39. Tonge DP, Pearson MJ, Jones SW. The hallmarks of osteoarthritis and the potential to develop personalised disease-modifying pharmacological therapeutics. Osteoarthritis Cartilage. 2014;22(5):609-621.

40. Gimble J, Guilak F. Adipose-derived adult stem cells: isolation, characterization, and differentiation potential. Cytotherapy. 2003;5(5): 362-369.

41. Wickham MQ, Erickson GR, Gimble JM, Vail TP, Guilak F. Multipotent stromal cells derived from the infrapatellar fat pad of the knee. Clin Orthop Relat Res. 2003;(412):196-212.

42. Zuk PA, Zhu M, Ashjian P, et al. Human adipose tissue is a source of multipotent stem cells. Mol Biol Cell. 2002;13(12):4279-4295.

43. Jo CH, Lee YG, Shin WH, et al. Intra-articular injection of mesenchymal stem cells for the treatment of osteoarthritis of the knee: a proof-ofconcept clinical trial. Stem Cells. 2014;32(5):1254-1266.

44. Winter A, Breit S, Parsch D, et al. Cartilage-like gene expression in differentiated human stem cell spheroids: a comparison of bone marrow-derived and adipose tissue-derived stromal cells. Arthritis Rheum. 2003;48(2):418-429.

45. Filardo G, Madry H, Jelic M, Roffi A, Cucchiarini M, Kon E. Mesenchymal stem cells for the treatment of cartilage lesions: from preclinical findings to clinical application in orthopaedics. Knee Surg Sports Traumatol Arthrosc. 2013;21(8):1717-1729.

46. Jeon D, Chu K, Lee ST, et al. A cell-free extract from human adipose stem cells protects mice against epilepsy. Epilepsia. 2011;52(9): 1617-1626.

47. Nagasawa H, Little JB. Induction of sister chromatid exchanges by extremely low doses of alpha-particles. Cancer Res. 1992;52(22) 6394-6396.

48. Martino G, Pluchino S. The therapeutic potential of neural stem cells. Nat Rev Neurosci. 2006;7(5):395-406

49. Kang SK, Shin MJ, Jung JS, Kim YG, Kim CH. Autologous adipose tissue-derived stromal cells for treatment of spinal cord injury. Stem Cells Dev. 2006;15(4):583-594.

50. Lalu MM, McIntyre L, Pugliese C, et al; Canadian Critical Care Trials Group. Safety of cell therapy with mesenchymal stromal cells (SafeCell): a systematic review and meta-analysis of clinical trials PLoS One. 2012;7(10):e47559.

51. García-Olmo D, García-Arranz M, Herreros D, Pascual I, Peiro C, Rodríguez-Montes JA. A phase I clinical trial of the treatment of Crohn's fistula by adipose mesenchymal stem cell transplantation. Dis Colon Rectum. 2005;48(7):1416-1423.

52. Garcia-Olmo D, Herreros D, Pascual I, et al. Expanded adipose-derived stem cells for the treatment of complex perianal fistula: a phase II clinical trial. Dis Colon Rectum. 2009;52(1):79-86.

53. Kim WS, Park BS, Sung JH. The wound-healing and antioxidant effects of adipose-derived stem cells. Expert Opin Biol Ther. 2009;9(7): 879-887.

54. Mori R, Tanaka K, de Kerckhove M, et al. Reduced FOXO1 expression accelerates skin wound healing and attenuates scarring. Am J Pathol. 2014;184(9):2465-2479.

55. Forcheron F, Agay D, Scherthan H, et al. Autologous adipocyte derived stem cells favour healing in a minipig model of cutaneous radiation syndrome. PLoS One. 2012;7(2):e31694.

56. Atalay S, Coruh A, Deniz K. Stromal vascular fraction improves deep partial thickness burn wound healing. Burns. 2014;40(7):1375-1383.

57. Rigotti G, Marchi A, Galiè M, et al. Clinical treatment of radiotherapy tissue damage by lipoaspirate transplant: a healing process mediated by adipose-derived adult stem cells. Plast Reconstr Surg. 2007;119(5): 1409-1422; discussion 1423-1404.

58. Irani Y, Casanova D, Amar E. [Autologous fat grafting in radiated tissue prior to breast prosthetic reconstruction: is the technique reliable?]. Ann Chir Plast Esthet. 2012;57(1):59-66. French.

59. Salgarello M, Visconti G, Farallo E. Autologous fat graft in radiated tissue prior to alloplastic reconstruction of the breast: report of two cases. Aesthetic Plast Surg. 2010;34(1):5-10.
60. Mazo M, Araña M, Pelacho B, Prosper F. Mesenchymal stem cells and cardiovascular disease: a bench to bedside roadmap. Stem Cells Int. 2012;2012:175979.

61. Ma T. Mesenchymal stem cells: from bench to bedside. World J Stem Cells. 2010;2(2):13-17.

62. Panfilov IA, de Jong R, Takashima S, Duckers HJ. Clinical study using adipose-derived mesenchymal-like stem cells in acute myocardial infarction and heart failure. Methods Mol Biol. 2013;1036:207-212.

63. Gnecchi M, Zhang Z, Ni A, Dzau VJ. Paracrine mechanisms in adult stem cell signaling and therapy. Circ Res. 2008;103(11):1204-1219.

64. Rasmussen JG, Frøbert O, Holst-Hansen C, et al. Comparison of human adipose-derived stem cells and bone marrow-derived stem cells in a myocardial infarction model. Cell Transplant. 2014;23(2):195-206.

65. Houtgraaf JH, den Dekker WK, van Dalen BM, et al. First experience in humans using adipose tissue-derived regenerative cells in the treatment of patients with ST-segment elevation myocardial infarction. J Am Coll Cardiol. 2012;59(5):539-540.

66. Ghasemi N, Razavi S. Transdifferentiation potential of adipose-derived stem cells into neural lineage and their application. Journal of Histology and Histopathology. 2014;1(1):1-5.

67. Faroni A, Rothwell SW, Grolla AA, Terenghi G, Magnaghi V, Verkhratsky A. Differentiation of adipose-derived stem cells into Schwann cell phenotype induces expression of $\mathrm{P} 2 \mathrm{X}$ receptors that control cell death. Cell Death Dis. 2013;4:e743.

68. Liao D, Gong P, Li X, Tan Z, Yuan Q. Co-culture with Schwann cells is an effective way for adipose-derived stem cells neural transdifferentiation. Arch Med Sci. 2010;6(2):145-151.

69. Yang L, Fang JS, Wang W, Chen RK, Shen CF. Transplantation of Schwann cells differentiated from adipose-derived stem cells modifies reactive gliosis after contusion brain injury in rats. $J$ Int Med Res. 2011;39(4):1344-1357.

70. Han C, Zhang L, Song L, et al. Human adipose-derived mesenchymal stem cells: a better cell source for nervous system regeneration. Chin Med J (Engl). 2014;127(2):329-337.

71. Carpentier PA, Palmer TD. Immune influence on adult neural stem cell regulation and function. Neuron. 2009;64(1):79-92.

72. Chang KA, Kim HJ, Joo Y, Ha S, Suh YH. The therapeutic effects of human adipose-derived stem cells in Alzheimer's disease mouse models. Neurodegener Dis. 2014;13(2-3):99-102.

73. Spinal cord injury. Fact sheet $N^{\circ} 384$ [webpage on the Internet]. Geneva: World Health Organization; 2013. Available from: http://www.who.int/ mediacentre/factsheets/fs384/en/. Accessed May 23, 2015.

74. Dasari VR, Veeravalli KK, Dinh DH. Mesenchymal stem cells in the treatment of spinal cord injuries: a review. World J Stem Cells. 2014;6(2):120-133.

75. Zhang HT, Cheng HY, Cai YQ, et al. Comparison of adult neurospheres derived from different origins for treatment of rat spinal cord injury. Neurosci Lett. 2009;458(3):116-121.

76. Tzouvelekis A, Paspaliaris V, Koliakos G, et al. A prospective, nonrandomized, no placebo-controlled, phase Ib clinical trial to study the safety of the adipose derived stromal cells-stromal vascular fraction in idiopathic pulmonary fibrosis. J Transl Med. 2013;11:171.

77. Karaoz E, Okcu A, Ünal ZS, Subasi C, Saglam O, Duruksu G. Adipose tissue-derived mesenchymal stromal cells efficiently differentiate into insulin-producing cells in pancreatic islet microenvironment both in vitro and in vivo. Cytotherapy. 2013;15(5):557-570.

78. Vanikar AV, Dave SD, Thakkar UG, Trivedi HL. Cotransplantation of adipose tissue-derived insulin-secreting mesenchymal stem cells and hematopoietic stem cells: a novel therapy for insulin-dependent diabetes mellitus. Stem Cells Int. 2010;2010:582382.

79. Tholpady SS, Ogle RC, Katz AJ. Adipose stem cells and solid organ transplantation. Curr Opin Organ Transplant. 2009;14(1):51-55.

80. Mizuno $H$. The potential for treatment of skeletal muscle disorders with adipose-derived stem cells. Curr Stem Cell Res Ther. 2010;5(2): 133-136.

81. Rodriguez AM, Pisani D, Dechesne CA, et al. Transplantation of a multipotent cell population from human adipose tissue induces dystrophin expression in the immunocompetent mdx mouse. $J$ Exp Med. 2005;201(9):1397-1405. 
82. Vieira NM, Brandalise V, Zucconi E, et al. Human multipotent adiposederived stem cells restore dystrophin expression of Duchenne skeletalmuscle cells in vitro. Biol Cell. 2008;100(4):231-241.

83. Pearse DD, Bunge MB. Designing cell- and gene-based regeneration strategies to repair the injured spinal cord. J Neurotrauma. 2006; 23(3-4):438-452.

84. Rombouts WJ, Ploemacher RE. Primary murine MSC show highly efficient homing to the bone marrow but lose homing ability following culture. Leukemia. 2003;17(1):160-170.

85. Shi M, Li J, Liao L, et al. Regulation of CXCR4 expression in human mesenchymal stem cells by cytokine treatment: role in homing efficiency in NOD/SCID mice. Haematologica. 2007;92(7):897-904.

86. Thangarajah H, Vial IN, Chang E, et al. IFATS collection: adipose stromal cells adopt a proangiogenic phenotype under the influence of hypoxia. Stem Cells. 2009;27(1):266-274.

87. Bobis-Wozowicz S, Miekus K, Wybieralska E, et al. Genetically modified adipose tissue-derived mesenchymal stem cells overexpressing CXCR4 display increased motility, invasiveness, and homing to bone marrow of NOD/SCID mice. Exp Hematol. 2011;39(6):686-696. e4.

88. Cho HH, Kyoung KM, Seo MJ, Kim YJ, Bae YC, Jung JS. Overexpression of CXCR4 increases migration and proliferation of human adipose tissue stromal cells. Stem Cells Dev. 2006;15(6):853-864.

89. Gauglitz GG, Jeschke MG. Combined gene and stem cell therapy for cutaneous wound healing. Mol Pharm. 2011;8(5):1471-1479.

90. Branski LK, Gauglitz GG, Herndon DN, Jeschke MG. A review of gene and stem cell therapy in cutaneous wound healing. Burns. 2009;35(2):171-180.

91. Lin G, Wang G, Liu G, et al. Treatment of type 1 diabetes with adipose tissue-derived stem cells expressing pancreatic duodenal homeobox 1. Stem Cells Dev. 2009;18(10):1399-1406.

92. Herberts CA, Kwa MS, Hermsen HP. Risk factors in the development of stem cell therapy. J Transl Med. 2011;9:29.

93. Dragoo JL, Lieberman JR, Lee RS, et al. Tissue-engineered bone from BMP-2-transduced stem cells derived from human fat. Plast Reconstr Surg. 2005;115(6):1665-1673.

94. Hoke NN, Salloum FN, Kass DA, Das A, Kukreja RC. Preconditioning by phosphodiesterase- 5 inhibition improves therapeutic efficacy of adipose-derived stem cells following myocardial infarction in mice. Stem Cells. 2012;30(2):326-335.

95. Uemura R, Xu M, Ahmad N, Ashraf M. Bone marrow stem cells prevent left ventricular remodeling of ischemic heart through paracrine signaling. Circ Res. 2006;98(11):1414-1421.

96. Cihova M, Altanerova V, Altaner C. Stem cell based cancer gene therapy. Mol Pharm. 2011;8(5):1480-1487.

97. Casiraghi F, Remuzzi G, Abbate M, Perico N. Multipotent mesenchymal stromal cell therapy and risk of malignancies. Stem Cell Rev. 2013;9(1):65-79.
98. Freese KE, Kokai L, Edwards RP, et al. Adipose-derived stems cells and their role in human cancer development, growth, progression, and metastasis: a systematic review. Cancer Res. 2015;75(7): 1161-1168.

99. Grisendi G, Bussolari R, Cafarelli L, et al. Adipose-derived mesenchymal stem cells as stable source of tumor necrosis factorrelated apoptosis-inducing ligand delivery for cancer therapy. Cancer Res. 2010;70(9):3718-3729.

100. Stuckey DW, Shah K. Stem cell-based therapies for cancer treatment: separating hope from hype. Nat Rev Cancer. 2014;14(10):683-691.

101. Choi SA, Lee JY, Wang KC, et al. Human adipose tissue-derived mesenchymal stem cells: characteristics and therapeutic potential as cellular vehicles for prodrug gene therapy against brainstem gliomas. Eur J Cancer. 2012;48(1):129-137.

102. Altaner C, Altanerova V, Cihova M, et al. Complete regression of glioblastoma by mesenchymal stem cells mediated prodrug gene therapy simulating clinical therapeutic scenario. Int J Cancer. 2014; 134(6):1458-1465.

103. Lin CS, Lin G, Lue TF. Allogeneic and xenogeneic transplantation of adipose-derived stem cells in immunocompetent recipients without immunosuppressants. Stem Cells Dev. 2012;21(15):2770-2778.

104. Yañez R, Lamana ML, García-Castro J, Colmenero I, Ramírez M, Bueren JA. Adipose tissue-derived mesenchymal stem cells have in vivo immunosuppressive properties applicable for the control of the graft-versus-host disease. Stem Cells. 2006;24(11):2582-2591.

105. Leto Barone AA, Khalifian S, Lee WP, Brandacher G. Immunomodulatory effects of adipose-derived stem cells: fact or fiction? Biomed Res Int. 2013;2013:383685.

106. Patel KM, Crisostomo P, Lahm T, et al. Mesenchymal stem cells attenuate hypoxic pulmonary vasoconstriction by a paracrine mechanism. J Surg Res. 2007;143(2):281-285.

107. Rani S, Ryan AE, Griffin MD, Ritter T. Mesenchymal stem cell-derived extracellular vesicles: toward cell-free therapeutic applications. $\mathrm{Mol}$ Ther. 2015;23(5):812-823.

108. Arslan F, Lai RC, Smeets MB, et al. Mesenchymal stem cell-derived exosomes increase ATP levels, decrease oxidative stress and activate $\mathrm{PI} 3 \mathrm{~K} /$ Akt pathway to enhance myocardial viability and prevent adverse remodeling after myocardial ischemia/reperfusion injury. Stem Cell Res. 2013;10(3):301-312.

109. Srijaya TC, Ramasamy TS, Kasim NH. Advancing stem cell therapy from bench to bedside: lessons from drug therapies. J Transl Med. 2014; $12: 243$

110. Cahan P, Daley GQ. Origins and implications of pluripotent stem cell variability and heterogeneity. Nat Rev Mol Cell Biol. 2013; 14(6):357-368.
Stem Cells and Cloning: Advances and Applications

\section{Publish your work in this journal}

Stem Cells and Cloning: Advances and Applications is an international, peer-reviewed, open access journal. Areas of interest in stem cell research include: Embryonic stem cells; Adult stem cells; Blastocysts; Cordblood stem cells; Stem cell transformation and culture; Therapeutic cloning; Umbilical cord blood and bone marrow cells; Laboratory,

\section{Dovepress}

animal and human therapeutic studies; Philosophical and ethical issues related to stem cell research. This journal is indexed on CAS. The manuscript management system is completely online and includes a quick and fair peer-review system. Visit http://www.dovepress.com/ testimonials.php to read real quotes from published authors. 